Publisher policy allows this work to be made available in this repository. Published in Pluralism in Economics: Theory, History and Methodology (ed. by Salanti A, Screpanti E]), copyright Edward Elgar Publishing. The original publication is available at: $\underline{h t t p: / / w w w . e-e l g a r . c o . u k / b o o k e n t r y ~ m a i n . l a s s o ? c u r r e n c y=U S \& i d=900}$

The only uses of this work permitted are private study or research. 


\title{
Methodological pluralism and pluralism of method
}

\author{
Sheila C. Dow
}

\section{INTRODUCTION}

Pluralism is the philosophical position that the ultimate reality of the universe consists of a plurality of entities; it is an ontological position. But the concept of pluralism can be applied at a variety of levels: to the (epistemological) understanding of reality (whether its ultimate nature is a plurality or not), to the methods employed to theorize about that understanding of reality, to the methodology which sets the criteria for theory choice, and to the study of methodologies themselves. Pluralism has been advocated at all of these levels in economics discourse. But an understanding of what is entailed by methodological pluralism and pluralism of method has been hampered by lack of reference to epistemological and ontological foundations. In particular, pluralism takes on a different meaning in a closed-system mode of thought (as in mainstream economics) from its meaning in an open-system mode of thought (as in post-Keynesian economics or institutional/evolutionary economics). The former can be thought of as 'pure pluralism', as the dual of a monist position, while the latter involves a more limited, although crucial, pluralism.

It is the purpose of this chapter to attempt to distinguish pluralism at the different levels, and according to different ontological and epistemological positions, and to assess whether the validity of the pluralist position differs as between these different levels. It is concluded that a pure pluralist position is untenable at any level, but that a modified methodological pluralism is to be welcomed if grounded in an appropriate ontological and epistemic position, i.e. that reality and knowledge of it are understood as open systems.

\section{OPEN AND CLOSED SYSTEMS}

Much of the following argument rests on the distinction between open and closed systems. Therefore, before considering pluralism as such, we consider first the nature of that distinction. An open system is one whose boundaries are not predetermined. Further, the nature and range of its constituent variables and the structure of their interrelationships are not predetermined. This is not a matter of stochastic variation. In contrast, the boundaries of a closed system are predetermined, as are the full range of constituent variables and the structure of their interrelationships. This does not preclude the possibility of stochastic variation. While closed systems are the province of classical logic, open systems are the province of a broader system of logic - ordinary logic, or human logic, as exemplified by Keynes (1973). While including classical logic as a special case for application under conditions of certainty, ordinary logic can also be applied to conditions of uncertainty, as pertain in open systems.

At the ontological level, the system is a system of real processes and phenomena. An understanding of reality as conforming to an open system may involve notions of human creativity and freedom of choice, for example. A closed-system understanding of reality may involve the notion of a grand plan on the part of the deity, and the absence of free will. Knowledge systems applied to this reality may be open or closed in either case. On the face of it, it might seem that an open-system ontology would entail an open-system epistemology, and similarly for a closed-system ontology. But, even if reality is an open system, it can be argued that knowledge can only be acquired by proceeding as if reality were a closed system. Alternatively, even if reality is a closed system, it can be argued that human knowledge inevitably cannot encompass the full system, so that it must itself conform to an open system.

General equilibrium theorizing is a fine example of a closed-system theoretical structure. Variables are clearly defined with fixed meaning, and the boundaries of the system are well defined according to which variables are endogenous and which exogenous. The aim is to reach agreement on the best representation of the structural relationships between variables, for universal application. This entails conformity of 
representation through formalism. The appraisal criterion of conformity to the principles of classical logic reflects a closed-system epistemology; where the additional criterion is applied of goodness of fit in econometric testing, a closed-system ontology is evident.

If reality is an open system, then any closed theoretical system can only have partial application. Formal systems are necessarily closed, since it is necessary to give variables fixed meaning, and to specify structural relationships and the exogenous variables. Other methods, however, can themselves be open; verbal analysis in particular allows for shades of meaning.

Once we move away from a closed-system ontology and/or a closed-system epistemology, the question of pluralism - its meaning and role - becomes interesting. If reality is an open system, how do we specify open systems of knowledge, and what role can closed subsystems of knowledge play? If knowledge is open (even if reality is closed), how do we choose the forms of (inevitably partial) knowledge to aim for? In what follows, we attempt to unravel the different possible senses of pluralism, and how they relate to different ontological and epistemological positions.

\section{ONTOLOGICAL PLURALISM}

Pluralism at the ontological level involves the belief that reality constitutes a plurality of entities. If this position is to be non-trivial, it involves a rejection of the notion of the unity of nature. In its pure form, ontological pluralism denies the existence of unifying forces in nature; if nature is pluralistic, then there is no scope for general theorizing. In economics, this position is most closely associated with postmodernism; postmodernism emphasizes fragmentation, even of the self (see Amariglio, 1988). Ontological pluralism entails epistemic pluralism (understanding is fragmented). Together these pluralisms deny any scope for theory (see Amariglio, 1990); indeed some postmodernists embrace the term 'nihilism' (see Amariglio and Ruccio, 1995), the term with which Gordon (1991) chooses to characterize pluralism. Similarly, they deny any role for methodology.

Yet the content of postmodernism belies these implications; general statements are made about reality, theories are put forward, and methodological statements made. In other words, pure ontological pluralism and its implications are untenable; any theoretical statement requires the belief in some regularity in understanding and/or in nature. The only possibilities then, if discourse is to occur at all, are a modified pluralism (partial regularities), or the belief in universal regularities. Many non-mainstream economists, other than postmodernists, hold a modified pluralist position, based on an organicist ontology (see for example Carabelli's (1995) account of Keynes's organicism). This position holds that there are regularities in nature which science should aim to identify, but that these regularities are of process rather than events (see Lawson, 1989, 1995); they cannot be isolated from evolutionary or other irregularities. The economy, like knowledge, is therefore best understood as an open system.

Mainstream economics on the other hand has traditionally seen its scope as being defined by universal regularities which can be separated dualistically from irregularities and are best understood within a closed theoretical system (see Dow, 1990a). Most mainstream economists, notably deductivists, are not explicit about their ontological position. But Lawson (1994) demonstrates that the view of science on which deductivism is based entails what he refers to as a 'Humean' ontology in terms of event regularities.

How far regularities can be perceived, if they exist, is an epistemic issue. We shall see in the next section that epistemic pluralism is not the sole preserve of ontological pluralists.

\section{EPISTEMIC PLURALISM}

Epistemic pluralism entails a plurality of understandings of reality; there is no known way of establishing what constitutes true knowledge. Logical positivism requires that theory be appraised with reference to an independent set of facts, implying that there is only one way in which (correctly) to know facts. Logical positivism came under serious threat in the 1960 s, a period in which the notion that authority had sole access to the truth was fundamentally questioned. In the philosophy of science, Popper's (1959) fallibilism had laid the groundwork, but it was Kuhn (1962) who captured the imagination with his argument that 
understanding is paradigm-specific; what appears to be contrary evidence may not be perceived as such if it threatens the power of the dominant paradigm.

Out of this change developed a distinctive perspective on understanding; this perspective is evident both in the rhetoric/hermeneutic approach as well as in postmodernism. Both take a pluralist position on understanding. The postmodernist epistemic pluralism follows directly from the postmodern pluralist ontology; even the individual has the potential for a plurality of understanding. The rhetoric/hermeneutic approach is inspired by Rorty's (1979) view that philosophy cannot mirror nature; no position is taken on whether ultimate reality is a plurality or not. (See the exchange between Mäki's (1988) attempt to tease out a rhetoric ontology, and McCloskey's (1988) reply.) Rather, understanding of reality is expressed by means of a plurality of narratives. Thus not only is reality discussed by means of a plurality of narratives, but that reality itself is to be read as a plurality of narratives (see Lavoie, 1990, Introduction, and Brown, 1994). There is no basis for choosing one narrative over another.

The logical positivist belief in a unitary objective understanding of facts nevertheless persists in much of economics (see Boland, 1991 and Lawson, 1994). The difficulty of devising definitive empirical tests has thrown increasing doubt on the truth-value of theory (see Boland, 1989, p. 88), but in general the truthvalue of the facts themselves is not questioned among mainstream economists. For the increasingly dominant deductivists, the truth-value of facts is seen as having relevance only regarding axioms, and these are asserted to be self-evident. A significant exception is the explicitly pluralist epistemic position taken by Weintraub (1989); his position has shifted from being Lakatosian (which as a basis for theory appraisal requires a unitary set of facts) to denying the scope for theory appraisal on the grounds that facts are theoryladen, i.e. there is a plurality of understanding of reality.

Epistemologically, there should be a direct parallel between a pluralist understanding (possibly of a pluralist reality) among economic agents and economists alike. This is the case for postmodernists and the rhetoric approach; there is no basis for choosing between understandings among agents or among economists. In contrast, the logical positivist position entails a unitary understanding of facts by agents and a corresponding unitary understanding by economists (though both may be expressed probabilistically). Curiously no such parallel is evident in Weintraub's work; if facts are theory-laden for economists, surely they must also be theory-laden for agents. An acceptance of this point would have profound implications for general equilibrium theorizing. It is the plurality of understanding by economic agents, in the postmodern view, which undermines theorizing in general.

Non-mainstream economists other than employers of postmodernism and the rhetoric approach (postKeynesians, or institutionalist/evolutionary economists, for example) employ an open-system epistemology which allows for a range of understandings but also for theorizing. Following directly from an organicist ontology, or from the view that human understanding of reality (whether ultimately organicist or not) is necessarily limited, it is argued that we can only understand reality as an open, organic system. Keynes's (1973) philosophy provides an epistemology for open organic systems; since knowledge in general is based on imperfect knowledge, it is inevitable that there will be a range of understandings of reality, among agents as well as economists. But this epistemology differs from pure pluralism in that there are regularities in the knowledge-generation process of agents and economists which limit the range of rational beliefs; the choice of belief (among agents and economists) is a matter for rational debate.

We now see how these different epistemologies feed through into positions on method, and then on methodology.

\section{PLURALISM OF METHOD}

Pluralism of method is the methodological position that there are no decisive criteria for selecting one best method of analysis (for example the deductivist method, or the experimental method); economists should therefore employ a plurality of methods. The major influence is Popper (1959) who saw a role for situational logic in the social sciences, given the difficulties with falsificationism; the choice of method should then be problem-dependent (see Caldwell, 1991, who also appears supportive of pluralism of method). This version of pluralism (also known as eclecticism) has been advocated by Hutchison (1988), Boland (1982) and Solow (1988) without any hint of pluralism at the epistemic or ontological levels; all 
three subscribe to a unitary epistemology and ontology. But if there is unitary understanding of such regularities as can be perceived (i.e. the epistemology and ontology conform to those of logical positivism) then pluralism of method can only be explained in terms of the failure of traditional methodology to produce satisfactory criteria for choosing methods. Practising economists must choose methods by some criteria; on what grounds are these criteria to be selected? In principle, it should be possible to construct a taxonomy of problem-types and advocate methods accordingly, given the starting point that economics aims to identify regularities that are presumed to exist. Boland (1989) takes case studies to illustrate the process of method choice. Mayer (1993) advocates a particular set of criteria based on the distinction between pure and applied theory. He advocates internal, formalist criteria for deductive theory and client satisfaction for empirical theory. But without any epistemological explanation for the need for a range of methods, given a unitary ontology and epistemology, a body of thought made up of pure theory and applied theory, with no explicit connection between the two, appears simply incoherent.

It might seem that pluralism of method could be justified by a pluralist epistemology. Since reality may be understood in a variety of ways, and there are no grounds for preferring one understanding over another, there are no grounds for choosing one method of acquiring knowledge over another. The rhetoric/hermeneutic approach takes an agnostic position (different methods are taken on their own merits but there is no advocacy of pluralism, indeed there is a denial of methodology in general). The postmodernist approach might be interpreted as advocating a plurality of methods; one of its most notable features is the denial of general theories. But, as has been suggested above, any postmodern position on method is self-contradictory; the essence of postmodernism is to eschew normative statements, and indeed theory in general.

The advocacy of a range of methods is entailed by the open-system epistemology of approaches such as that adopted by post-Keynesian economists, or institutional/evolutionary economists. But this is not pluralism of method in the eclecticism sense, although it is commonly misunderstood by others as such. It is entailed by an open-system epistemology that knowledge is acquired by gathering evidence and constructing arguments in order to build up rational belief. These contributions to knowledge are incommensurate in the sense that they do not build up to a single probability statistic, i.e. they do not fit into closed-system theorizing. Certainly the choice of a range of methods depends on the nature of the problem and the context. But the choice is guided (and thus limited) by reason, by convention and by vision; it is differences in these that account for different schools of thought which have in common open-system theorizing (see Dow, 1990b). To distinguish this approach from that of the eclecticists, it must be emphasized that reason, conventions and vision all take on a particular meaning and play an explicit part in open-system epistemology (terms do not have unitary meaning). Closed-system reason is only a subset of open-system reason (see Carabelli, 1988). Conventions are a necessity in building up knowledge in Keynesian logic (see Hodgson, 1988), while in mainstream epistemology they lack logical foundation, as Boland (1982) has tirelessly pointed out. Finally, vision (or ontology) determines how problems are identified and interpreted (see Dow, 1990b). Given an open-system ontology, there is a range of possibilities; given a closed-system, unitary ontology, there is only one.

\section{METHODOLOGICAL PLURALISM}

Methodological pluralism is a meta-methodological position; it advocates that methodologists study a range of methodologies (by means of rational reconstruction). Critical pluralism involves the criticism of this range of methodologies by means of a range of criteria. This position has been advocated most notably by Caldwell (1982, 1986, 1988). The underlying reasoning is that there is no basis for deciding on one methodology. Rather than devoting fruitless efforts to finding the best methodology, methodologists should devote their efforts to promoting methodological understanding among economists by clarifying the nature of the different possibilities and demonstrating their strengths and weaknesses according to different criteria. (Boland $(1982,1991)$ at times also seems to be a methodological pluralist as well as a pluralist of method. Redman (1991) advocates a critical rationalist version of methodological pluralism.)

Although this positive role for methodology counters the anti-methodology position of the rhetoric/hermeneutic approach, Caldwell (1990) embraces the hermeneutic idea of taking each approach on 
its own merits to promote a better understanding among practitioners of different approaches. The critical element is additional, however, and represents the fundamental meta-methodological difference from the hermeneutic approach. The rhetoric/hermeneutic approach accepts plurality of understanding and plurality of method as a description of reality, but refuses to make any normative judgement about the nature or extent of those pluralities; postmodernists positively welcome plurality of understanding and method (the more the better, as a reflection of a fundamentally fragmented reality). Caldwell, rather (from his Popperian starting point) appears to regard a wide plurality of methodologies as a regrettable necessity, and looks forward to the outcome of methodological pluralism as being a narrowing-down of possibilities (see Caldwell, 1989).

But, as was pointed out in the discussion of Caldwell's (1988) paper (see de Marchi, 1988, pp. 53-6), Caldwell does not spell out the epistemological foundations of his methodological pluralism (nor its ontological foundations). What is the reason for a range of methodologies in the first place? Is it in the nature of knowledge (and reality) that it be so, as the open-system approach suggests? Or is it a temporary limitation on our understanding, as the eclecticist approach suggests? Or is it pure folly that methodologies and methodologists persist at all in spite of the fragmentation of knowledge (and possibly reality) as the rhetoric approach and postmodernists suggest?

Critical methodological pluralism explicitly aims to go beyond description. But as with eclecticist pluralists, the question arises as to the criteria for criticism. Caldwell advocates particularly criticism in a methodology's own terms as a way of promoting greater understanding of a particular methodology. Such an effort is clearly preferable to the all-too-common criticism of one methodology by the criteria of another (see Caldwell, 1986). But it is only feasible up to a point. If the justification of methodological pluralism is epistemic, then, just as facts are theory-laden and theories are methodology-laden, so must the knowledge of methodologists be coloured by their own vision of reality and of how knowledge is constructed; epistemic pluralism, after all, is a recognition that there are different understandings of reality, but in general any one economist or methodologist only has one understanding. I can attest from personal experience of trying to present a range of schools of thought in their own terms (Dow, 1985) that it is not possible to switch fully satisfactorily in a detached fashion from one ontology-plus-epistemology to another. But without a pluralist epistemology, what is the justification for methodological pluralism?

While I share Caldwell's view that trying to understand different methodologies in their own terms is a worthwhile exercise and should serve to promote more constructive debate among economists, the scope for that understanding is always conditional on the methodologist's own ontological and epistemological position. This applies even more strongly to the application of external criteria, which must be chosen according to some further criteria if the exercise is to have meaning.

Caldwell's statements of methodological pluralism have tremendous appeal in their advocacy of civilized, reasoned, non-self-serving behaviour. But methodological pluralism, as presented so far, lacks force because of its lack of epistemic and ontological foundations. In traditional epistemic (i.e. dualist) terms, methodological pluralism can be interpreted as non-methodology because it does not establish standards. Understood as the dual of traditional methodology, methodological pluralism may be understood as according with the rhetoric approach, which denies methodology any role. But understood as a means of improving knowledge, where knowledge is understood as an open system, methodological pluralism is fully justified. Methodologists cannot escape their own preconceptions any more than anyone else. But an ontological and epistemic awareness can enhance awareness of these preconceptions, which in turn can enhance awareness among economists at large of their preconceptions.

\section{CONCLUSION}

I conclude therefore that methodological pluralism in a pure form, like pluralism of method, pluralist epistemology and pluralist ontology, is untenable as a basis for knowledge. Pure pluralism is taken here to be the dual of the traditional unitary position of mainstream economics. Further, the justification of methodological pluralism or pluralism of method is not at all clear when either is combined with a unitary, closed-system epistemology and/or ontology. On the other hand, the recognition of the inevitability of a 
range of methodologies and the advocacy of the employment of a particular range of methods is the logical outcome of an open-system epistemology and ontology.

This chapter is offered as an exercise in open-system meta-methodology. It offers an attempt at a rational reconstruction of a range of positions with respect to pluralism, in the full knowledge that these reconstructions may be flawed, not least because of my own preconceptions. But this is how knowledge progresses: offering arguments provides scope for feedback to correct misunderstandings and to direct modifications in thinking. Within an open-system approach there is no contradiction involved in arguing for one's own viewpoint while respecting and being open to the viewpoints of others.

\section{REFERENCES}

Amariglio, J.L. (1988), 'The Body, Economic Discourse, and Power: An Economist's Introduction to Foucault', History of Political Economy, 20 (4), pp. 583-613.

Amariglio, J.L. (1990), Economics as a Postmodern Discourse. In W.J. Samuels (ed.), Economics as Discourse, Boston: Kluwer.

Amariglio, J.L. and Ruccio, D.F. (1995), 'Keynes, Postmodernism and Uncertainty', in S.C. Dow and J. Hillard (eds), Keynes, Knowledge and Uncertainty, Aldershot: Edward Elgar.

Backhouse, R.E. (1988), 'The Value of Post Keynesian Economics: A Neo-Classical Response to Harcourt and Hamouda', Bulletin of Economic Research, 40 (1), pp. 35-41.

Boland, L.A. (1982), The Foundations of Economic Method, London: Allen \& Unwin.

Boland, L.A. (1989), The Methodology of Economic Model Building: Methodology After Samuelson, London: Routledge.

Boland, L.A. (1991), 'The Theory and Practice of Economic Methodology', Methodus, 3 (2), pp. 6-17.

Brown, V. (1994), 'The Economy as Text', in R.E. Backhouse (ed.), New Directions in Economic Methodology, London: Routledge.

Caldwell, B.J. (1982), Beyond Positivism: Economic Methodology in the Twentieth Century, London: Allen \& Unwin.

Caldwell, B.J. (1986), 'Towards a Broader Conception of Criticism', History of Political Economy, 18, pp. 675-81.

Caldwell, B.J. (1988), 'The Case for Pluralism', in N. De Marchi (ed.), The Popperian Legacy in Economics, Cambridge: Cambridge University Press.

Caldwell, B.J. (1989), 'Post-Keynesian Methodology: An Assessment', Review of Political Economy, 1 (1), pp. 43-64.

Caldwell, B.J. (1990), 'Does Methodology Matter? How Should it be Practiced?', Finnish Economic Papers, 3 (1), pp. 64-71.

Caldwell, B.J. (1991), 'Clarifying Popper', Journal of Economic Literature, 29 (1), pp. 1-33.

Carabelli, A. (1988), On Keynes's Method, London: Macmillan.

Carabelli, A. (1995), 'Uncertainty and Measurement in Keynes: Probability and Organicness', in S.C. Dow and J. Hillard (eds), Keynes, Knowledge and Uncertainty, Aldershot: Edward Elgar.

de Marchi, N. (ed.) (1988), The Popperian Legacy in Economics, Cambridge: Cambridge University Press.

Dow, S.C. (1985), Macroeconomic Thought: A Methodological Approach, Oxford: Blackwell.

Dow, S.C. (1990a), 'Beyond Dualism', Cambridge Journal of Economics, 14 (2), pp. 143-58.

Dow, S.C. (1990b), 'Post Keynesianism as Political Economy: A Methodological Discussion', Review of Political Economy, 2 (3), pp. 345-58.

Gordon, S. (1991), The History and Philosophy of Social Science, London: Routledge.

Hodgson, G.M. (1988), Economics and Institutions, Cambridge: Polity Press.

Hutchison, T.W. (1988), 'The Case for Falsification', in N. De Marchi (ed.), The Popperian Legacy in Economics, Cambridge: Cambridge University Press.

Keynes, J.M. (1973), The Treatise on Probability. Collected Writings, vol. VIII, London: Macmillan for the Royal Economic Society.

Kuhn, T.S. (1962), The Structure of Scientific Revolutions, Chicago: Chicago University Press.

Lavoie, D. (ed.) (1990), Economics and Hermeneutics, London: Routledge.

Lawson, T. (1989), 'Abstractions, Tendencies and Stylised Facts: A Realist Approach to Economic Analysis', Cambridge Journal of Economics, 13(1), pp. 59-78.

Lawson, T. (1994), 'Why Are So Many Economists Opposed to Methodology?', Journal of Economic Methodology, 1(1), pp. 105-34.

Lawson, T. (1995), 'Economics and Expectations', in S.C. Dow and J. Hillard (eds), Keynes, Knowledge and Uncertainty, Aldershot: Edward Elgar.

McCloskey, D.N. (1983), 'The Rhetoric of Economics', Journal of Economic Literature, 21, pp. 481-517.

McCloskey, D.N. (1988), 'Two Replies and a Dialogue on the Rhetoric of Economics: Mäki, Rappoport, Rosenberg', Economics and Philosophy 4 (1), pp. 150-66. 
Mäki, U. (1988), 'How to Combine Rhetoric and Realism in the Methodology of Economics', Economics and Philosophy, 4 (1), pp. 89-109.

Mayer, T. (1993), Truth Versus Precision in Economics, Aldershot: Edward Elgar.

Mehta, J. (1993), 'Meaning in the Context of Bargaining Games - Narratives in Opposition', in W. Henderson, T. Dudley Evans and R. Backhouse (eds), Economics and Language, London: Routledge.

Popper, K. (1959), The Logic of Scientific Discovery, London: Harper \& Row.

Redman, D.A. (1991), Economics and the Philosophy of Science, Oxford: Oxford University Press.

Rorty, R. (1979), Philosophy and the Mirror of Nature, Princeton: Princeton University Press.

Solow, R.M. (1988), 'Comments from Inside Economics', in A. Klamer, D. McCloskey and R.M. Solow (eds), The Consequences of Economic Rhetoric, Cambridge: Cambridge University Press.

Weintraub, E.R. (1989), 'Methodology Doesn't Matter, But the History of Economic Thought Might', Scandinavian Journal of Economics, 91, pp. 477-93. 